\title{
UAV SURVEY FOR THE ARCHAEOLOGICAL MAP OF LILYBAEUM (MARSALA, ITALY)
}

\author{
D. Ebolese ${ }^{1, *}$, M. Lo Brutto ${ }^{2}$, G. Dardanelli ${ }^{2}$ \\ ${ }^{1}$ Department Cultures and Societies, University of Palermo, Palermo, Italy, donatella.ebolese@unipa.it \\ ${ }^{2}$ Department of Engineering, University of Palermo, Palermo, Italy, (mauro.lobrutto, gino.dardanelli)@unipa.it
}

KEY WORDS: Archaeology, UAV, Photogrammetry, 3D Documentation, Archaeological map

\begin{abstract}
:
Collecting information and mapping are fundamental aspects of systematic archaeological excavation, documentation and interpretation. The process of recording physical evidence is the first step in the archaeological study with the goal to derive spatial and semantic information from the gathered and available data. Archaeological reports always include 2D maps, sections, data distribution and other spatial data. Indeed, the representation is inseparable from the archaeological practice, but this is undoubtedly a time-consuming activity. Nowadays, archaeologists can take advantages of various recording techniques to produce highly accurate 3D models and ortho-images of archaeological sites. Far from replacing the more traditional techniques, the development of new geomatics techniques tries to answer, in a more efficient way, to the needs of archaeological research. The use of Unmanned Aerial Vehicles (UAVs) has become more popular in archaeological excavations. In particular, UAV systems become a useful, versatile and cost-effective approach to record large archaeological areas in order to measure and completely document them. They are the fastest way to produce high-resolution 3D models of entire sites and allow archaeologists to collect accurate spatial data that can be used for spatial analyses using GIS platform. The paper presents the results of several UAV surveys of the archaeological remains of Lilybaeum, the ancient city of Marsala (Southern Italy), performed in the Archaeological Park of "Lilibeo". The UAV acquisitions were planned and carried out to complete the previous traditional documentation of the site. Very detailed 3D models and high-resolution ortho-images, together with some new field campaigns, have been used for new analysis and documentation of the site and for the realization of the archaeological map of Lilybaeum.
\end{abstract}

\section{INTRODUCTION}

Investigation and preservation of archaeological resources request appropriate, preferably non-invasive, and flexibility methods which should be suited to detailed documentation, regardless of the site extension and shape complexity (Tscharf et al., 2015). The development of technical capacities and potentialities of geomatics techniques can lead to new approaches by providing refinements for purposes coming from archaeological topics (Chiabrando et al. 2018).

The high-accuracy data, needed to document the archaeological remains, can be provided in an efficient and low-cost manner using the new aerial acquisition systems based on Unmanned Aerial Vehicles (UAVs) (Fernández-Hernandez et al., 2015). UAV-based documentation is increasingly seen as a standard, flexible and cost-effective tool applicable in different featured excavation areas (Cowley et al., 2017). UAV survey has given the opportunity to support traditional measurement methods and increased the number of tools to visualize archaeological remains (Lo Brutto et al., 2014); it can provide a suitable and replicable methodology to support archaeological study and to improve the interest in collecting low altitude aerial imagery. The use of UAV-based photogrammetry, for precise mapping of archaeological sites, presents many advantages, as the possibility of vertical or oblique view to cover large areas, the easy interpretation of the data, the possibility of threedimensional view and very accurate photogrammetric measuring (Nikolakopoulos et al., 2016).
UAV can be used in high-risk situations and reach inaccessible places by facilitating, over the years, a gradual transition from traditional methods to new acquisition techniques (Brumana et al., 2013). In particular, the advantages of multi-copter UAVs can close the gap between terrestrial close-range and aerial photogrammetry (Lo Brutto et al., 2017; Lo Brutto et al., 2018). Moreover, the development and improvement of various types of sensors, data processing methodologies and multi-resolution $3 \mathrm{D}$ representations provide archaeological documentation about both geometric features and material classification and an effective tool for cultural heritage monitoring (Erenoglu et al., 2017).

All involved steps, from the acquisition phase to the analysis phase, have to be strictly linked to information required and documentation purposes, in order to treat this new technology as part of the archaeological interpretation.

Due to their high performances, UAV surveys give the opportunities to obtain different products, such as 3D models, Digital Surface Models (DSMs) and ortho-images very useful for archaeological study. The data acquired from UAV not only increase the rapidity and the precision of archaeological investigation but allow to make information accessible and reproducible for different purposes (Herrmann et al., 2018). The information that can be derived from UAV dataset, allow interacting with archaeological data even after a long period of time, with the possibility not only to document them but also to carry out further studies (Bitelli et al., 2018). These products can become a suitable database on which it is possible to store

* Corresponding author 
other data from a geospatial perspective, to set comparative analysis and to support the development of archaeological maps.

The archaeological maps can be defined as "a tool for the management of the cultural heritage, planning and urban development, and are drawn upon the basis of existing studies and recent fieldwork, covering all the latest data" (Rocha \& Branco, 2009). An archaeological map becomes important as a means of protecting and conserving the known archaeological heritage and, as well as to provide guidelines for future research and activities.

The paper presents the ongoing activities related to the UAV surveys for the achievement of the archaeological map of Lylibaeum (Marsala, Southern Italy). The remains of Lilybaeum, the ancient city of Marsala, founded in the IV century B.C. by the Punic, are currently preserved in the archaeological Park of "Lilibeo" where a considerable area of the ancient city, as the ruins of the Decumanus maximus and several luxurious private buildings, are still visible.

The work is part of the research project "The Archaeological Map of Lilybaeum", conducted by the Laboratory of Geomatics of the Department of Engineering of the University of Palermo in partnership with the Department Cultures and Societies of the University of Palermo and the Department of Cultural Studies of the University of Hamburg.

The UAV surveys, started in 2017 , were carried out in order to achieve complete aerial documentation of the archaeological remains of the ancient Lylibaeum. An image-based reconstruction workflow, aimed at the realization of $2 \mathrm{D}$ and $3 \mathrm{D}$ data for the archaeological map of the site, was carried out to obtain high-resolution ortho-images and very detailed 3D models. Moreover, in specific areas not yet excavated, UAVbased thermal acquisitions have been performed to locate possible buried structures.

The 2D and 3D data from UAV surveys become useful support, together with all previous documentation of the archaeological remains, for the creation of the archaeological map of Lylibaeum. These georeferenced data enable a rigorous comparison of all archaeological features and serve as a background base to the production of new data (such as updated plans,...). Moreover, all these data can be stored, manipulated, analyzed and visualized in a GIS (Geographic Information System) environment. The use of a GIS approach helps the interpretation of data thanks to the possibility of overlapping and cross-checking information. It allows linking georeferenced $3 \mathrm{D}$ models to underlying data, in order to intertwine environmental and cultural factors to work towards new approaches (Richards-Rissetto, 2017). In archaeology, where data have a dual nature, as they are distributed both in space and time, this means a collection of material to achieve a diachronic interpretation of the evolution of an area.

\section{THE ARCHEOLOGICAL PARK OF "LILIBEO"}

The Archaeological Park of "Lilibeo" extends for about 28 hectares inside the city of Marsala (Figure 1). This wide area, spared by building expansion, preserves a considerable area of Lilybaeum, the ancient city of Marsala, founded in the IV century B.C. by the Punic. The city occupies the westernmost promontory of Sicily, in a strategic position that was its strong point since its foundation. On all four sides, the city, with a quadrangular shape, was surrounded by imposing walls; it was also protected by the sea on two sides and by a moat on the other two sides. The ancient city of Lilybaeum was an impregnable military base until the Roman conquest in 241 B.C.
Since the end of the XIX century, the discovery of important archaeological remains, which attest the long and intense life of the city over centuries, has captured the interest of archaeologists.

Currently, the ruins of the Decumanus maximus and several luxurious private buildings, with a wealth of thermal baths and polychrome mosaics, show the Lilybaeum prosperity until the Roman Empire.

Within the walls, the Decumanus maximus crossed the city; parallel and orthogonal to the main street decumani minores and cardines cut the quarters up into blocks.

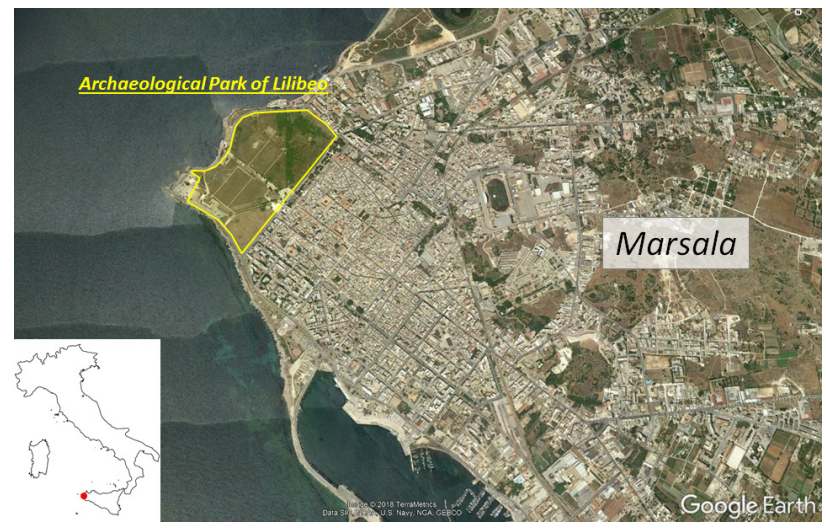

Figure 1. Archaeological Park of "Lilibeo" (from Google Earth(C).

In recent years, a paved section of the Decumanus maximus, ca. $115 \mathrm{~m}$ long and $10 \mathrm{~m}$ wide, was brought to light (Giglio, 2011). Traces of a Latin inscription, originally in bronze, found on some of the Decumanus slabs, seem to attribute to an anonymous magistrate (praetor designates) the paving of the main street. Between the V and VII century A.D., the Decumanus maximus was used for a funerary function.

The most important remains of private and decorated buildings are located in the north-east area of the Park, where are still visible the archaeological area of the Insulae I, II and III. In particular, the Roman domus, excavated first in 1939, completely occupies the area of the Insula I. Probably, in a first phase, II-I centuries A.D., the Insula I was characterized by three different sectors: two houses, divided by a narrow street (ambitus), on the north and south sides of the Insula and some commercial rooms on the west. In the Roman-Imperial period (end of II- beginning of the III century A.D.) the Insula organization was radically transformed and the two previous houses became a single large domus. The domus is characterized by many rooms and thermal baths and it is decorated with polychrome mosaics, some of which are still in situ.

Another important archaeological testimony of the life of the ancient Roman city is the presence of a large building located in the north-east area of the Insula III. Probably, since its first phase, dated to the II century B.C, it was a religious building. In the second half of the II century A.D. the building was dedicated to the cult of Isis. It is characterized by various rooms, some of which decorated with floor mosaics. Near the podium, located in the central room, were found fragments of inscriptions and of statues, one of which is dedicated to Isis. In the south-west area of the Park, other important archaeological remains were located near the church of "San Giovanni”.

In the north-west area of the Park, the archaeological remains of the fortifications system confirm the impressive role of the city 
walls. Moreover, in this area, the presence of a monumental entrance from the harbor was documented. The walls structure had a double curtain; it was equipped with an upper walkway and defended by semicircular merlons. Near the monumental entrance, excavations brought to light a large tower on which, when the city walls lost their function, thermal baths were built. Of this thermal building, there is still in situ the underground environment of the hypocaustum and a large apsidal room (Giglio \& Vecchio, 2004).

\section{THE UAV SURVEY}

The UAV survey was organized in different phases: the topographic survey, the flights planning and flights execution, the data processing. Operations involved the archaeological remains of (Figure 2)

- $\quad$ Insulae I, II and III;

- Decumanus maximus;

- archaeological area of "San Giovanni";

- $\quad$ area of north-western fortifications and thermal baths.

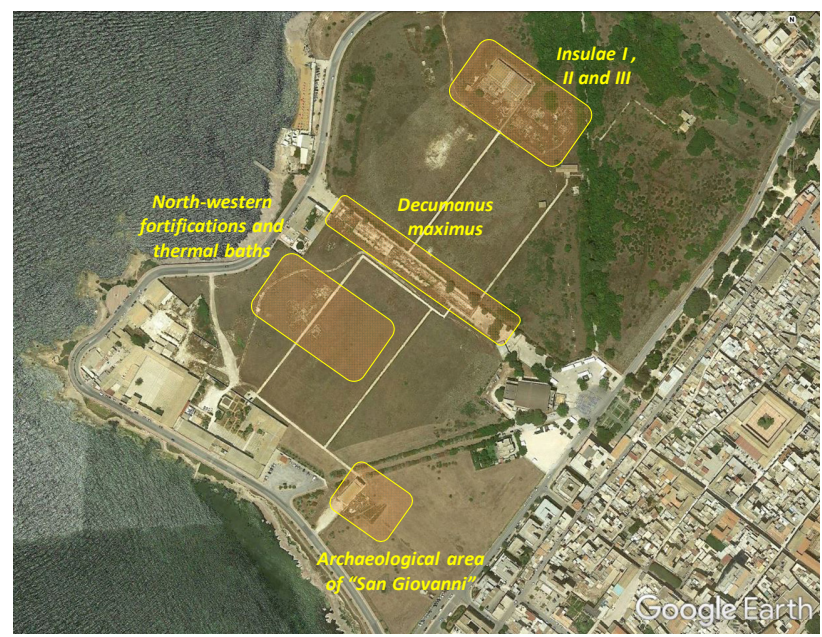

Figure 2. The areas of the UAV surveys (from Google Earth $\subset$ ).

\subsection{The topographic survey}

Accurate topographic measurements by total station and GNSS were carried out in order to establish a topographic network and to geo-reference data in a cartographic reference system.

A topographic network of 8 points was realized inside the archaeological Park; the network was located in the central part of the Park and was measured with a Leica TPS 1105 total station (accuracies: angle 5", distances $2 \mathrm{~mm}+2 \mathrm{ppm}$ ) (Figure $3)$. The network was calculated in a local reference system obtaining a Root Mean Square Error (RMSE) of $\pm 0.007 \mathrm{~m}$ for planimetric coordinates and of $\pm 0.003 \mathrm{~m}$ for the height.

Three points were also measured with a static GNSS survey, with a Topcon Hiper $\mathrm{V}$ receiver, to reach their cartographic coordinates. The static survey was performed using the data from the Italian Continuously Operating Reference Stations (CORS) NetGEO. The GNSS measurements were georeferenced in the Italian national geodetic reference system RDN2008-ETRF2000, using the UTM projection. To convert the coordinates of the topographic network from the local reference system to the Italian national geodetic reference system, the coordinates of these three points were used to calculate the roto-translation parameters; the ellipsoid heights were also transformed to orthometric heights using the information of the Italian geoid model.

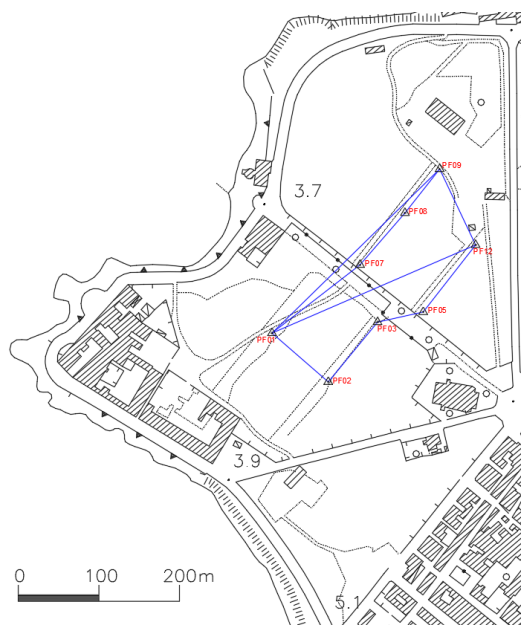

Figure 3. The topographic network.

\subsection{Flights planning and flights execution}

The flights were performed on different days; the first UAV surveys were carried out in the areas of the Insulae and of the Decumanus maximus; the subsequent surveys were conducted on the archaeological area of "San Giovanni" and on the area of north-western fortifications and thermal baths. To guarantee a centimetric or sub-centimetric accuracy, different flying heights were planned according to the characteristics and the size of the surveyed areas.

The flying height for the Insulae and the Decumanus maximus was fixed at $25 \mathrm{~m}$, with a resulting average Ground Sampling Distance (GSD) of $5.5 \mathrm{~mm}$ (Figures 4 and 5).

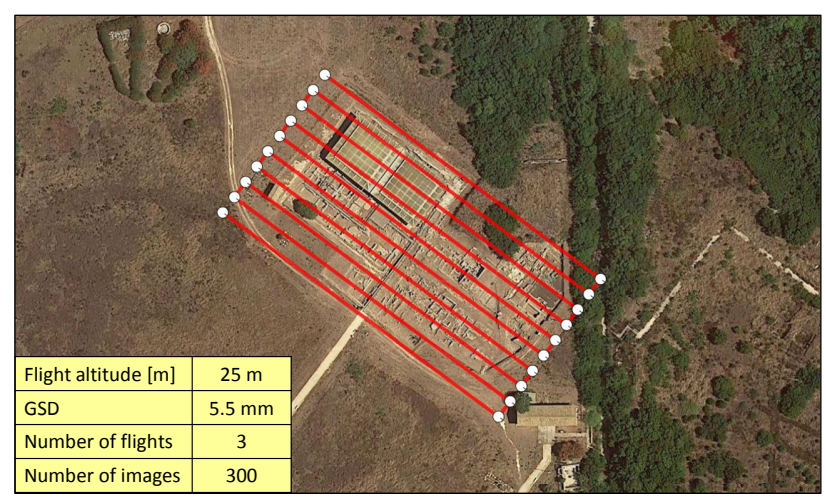

Figure 4. Flight specifications for the Insulae.

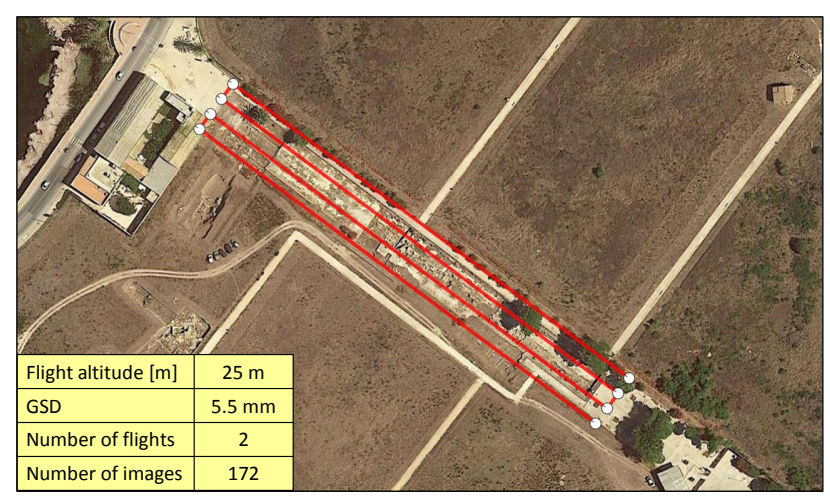

Figure 5. Flight specifications for the Decumanus maximus. 
The flying height for the archaeological area of "San Giovanni" was of $7 \mathrm{~m}$, with an average GSD of $1.6 \mathrm{~mm}$ (Figure 6) and, finally, the last flight, above the area of north-western fortifications and thermal baths, was carried out from a height of $15 \mathrm{~m}$, obtaining a GSD of $3.3 \mathrm{~mm}$ (Figure 7). All flights were planned to capture images with a forward and side overlap of $70 \%$.

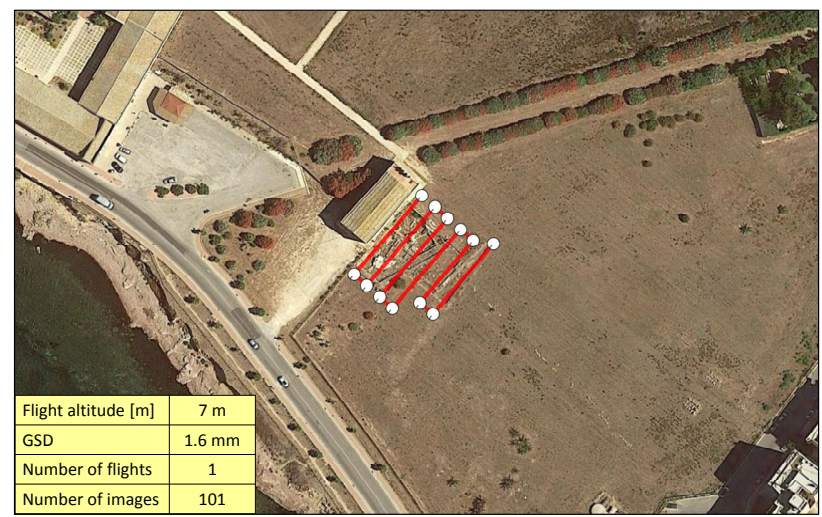

Figure 6. Flight specifications for the archaeological area of "San Giovanni".

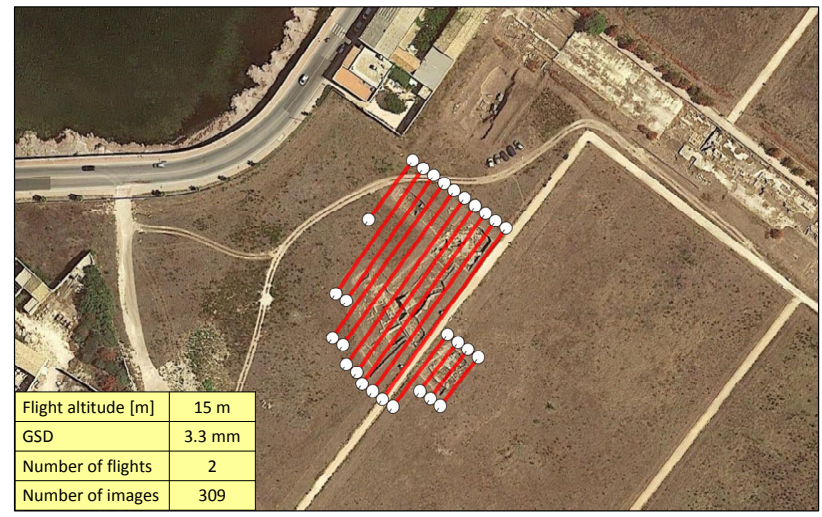

Figure 7. Flight specifications for the area of north-western fortifications and thermal baths.

In the area of north-western fortifications and thermal baths, a flight with a thermal camera was also carried out in order to detect probably buried structures. The use of UAV with a thermal digital sensor allows thermal prospection for archaeological detection at low altitude with high-resolution information (Poirier et al., 2013).

The aerial data acquisition was performed with an Aibot X6 V2 hexacopter produced by Aibotix $\mathrm{GmbH}$ equipped with a mirrorless digital camera Olympus PEN E-PL5 with a lens of $17 \mathrm{~mm}$.

Due to the dimensions of the structures to be detected (whose height hardly ever exceeds one meter), all photogrammetric flights were carried out with the camera oriented in the nadir direction (Figure 8).

Before the flights some photogrammetric targets (with dimensions of $20 \mathrm{~cm} \times 20 \mathrm{~cm}$ and $10 \mathrm{~cm} \mathrm{x} 10 \mathrm{~cm}$ ) were deployed on the ground as suitable control points. The coordinates of these points were measured using the total station. The number and position of the targets were decided on the basis of the size and shape of the archaeological area to be surveyed.

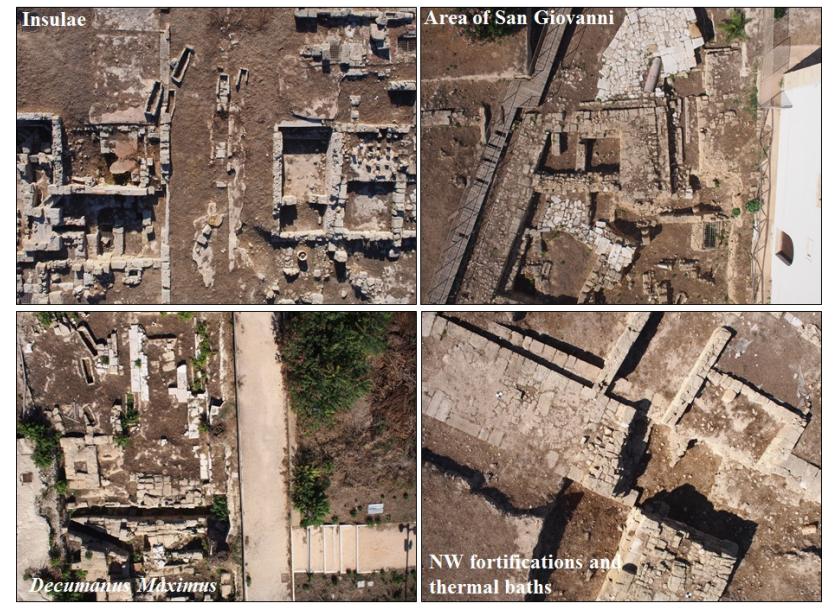

Figure 8. UAV nadiral images of the Insulae, the Decumanus maximus, the area of "San Giovanni" and the area of northwestern fortifications and thermal baths.

Images were acquired in autonomous mode according to a scheduled interval of 3 seconds for the flights of the Insulae and the Decumanus maximus, and of 1 second for the flights of the archaeological area of "San Giovanni" and of the area of northwestern fortifications and thermal baths. The ground speed of the UAV has been set to always ensure a forward overlap of at least $70 \%$

A total amount of more 900 images were acquired over the archaeological area of "Lilibeo".

The thermal inspection was realized equipped the Aibot X6 V2 hexacopter with an Optris PI 450 LightWeight thermal camera. Some flights from an altitude of $25 \mathrm{~m}$ were performed at different times of the day. Thermal camera acquired video with a GSD of about $8 \mathrm{~cm}$.

\subsection{Data processing}

While the thermal images have not yet been processed, all the acquired images, in the visible range, were processed by a photogrammetric workflow, based on Structure from Motion techniques (SfM). In order to reconstruct accurate 3D models, a classical pipeline was carried out by performing the following steps: feature extraction and matching, automatic image orientation by SfM, bundle block adjustment to calculate the camera calibration parameters and the exterior orientation parameters, dense image matching to generate 3D point cloud, mesh and DSM generation, texturing and ortho-image production.

Two of the most popular commercial software packages were used for image processing; Pix4DMapper (v. 4.1.22) was employed for the Insulae and the Decumanus maximus surveys (Figure 9 and 10); Agisoft PhotoScan Professional (v. 1.3.4) was instead used for the archaeological area of "San Giovanni" and for the area of north-western fortifications and thermal baths (Figures 11 and 12).

The coordinates of the targets, measured with the topographic survey, were used as GCPs and as checkpoints (CPs) during the orientation step to evaluate the image orientation accuracy. The accuracy of each project was evaluated by considering the RMSE of GCPs and CPs (Table 1).

In order to provide useful and accurate products for archaeological purposes, 3D point clouds, textured meshes and ortho-images were realized. 


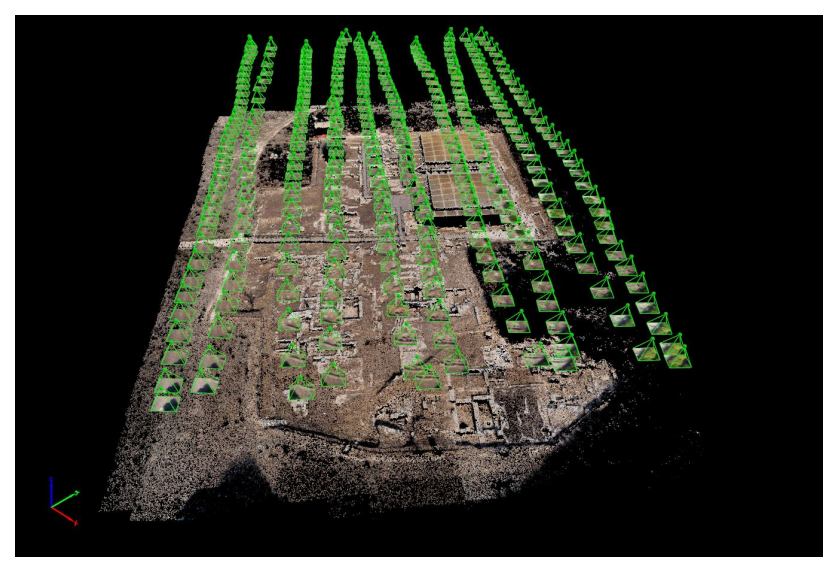

Figure 9. Camera position of the Insulae flight.

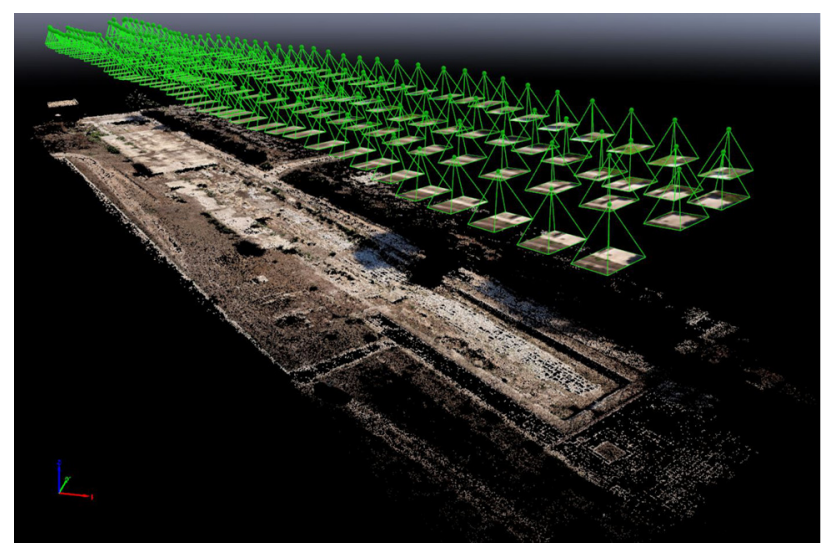

Figure 10. Camera position of the Decumanus maximus flight.

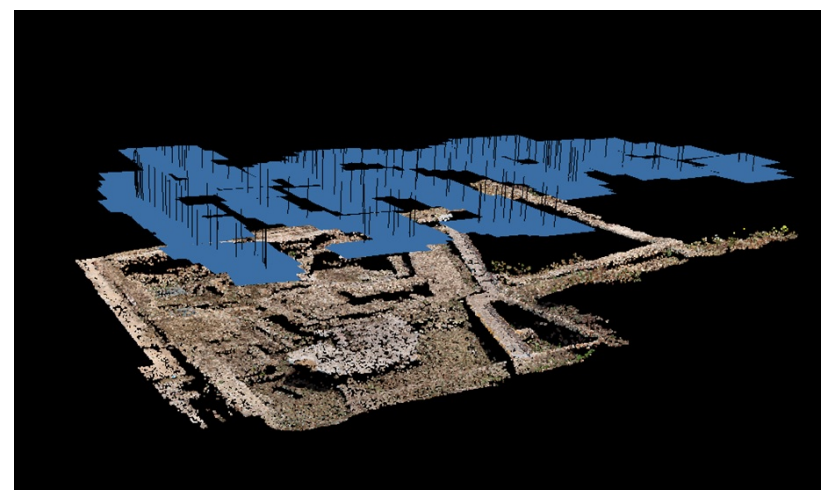

Figure 11. Camera position of the area of "San Giovanni" flight.

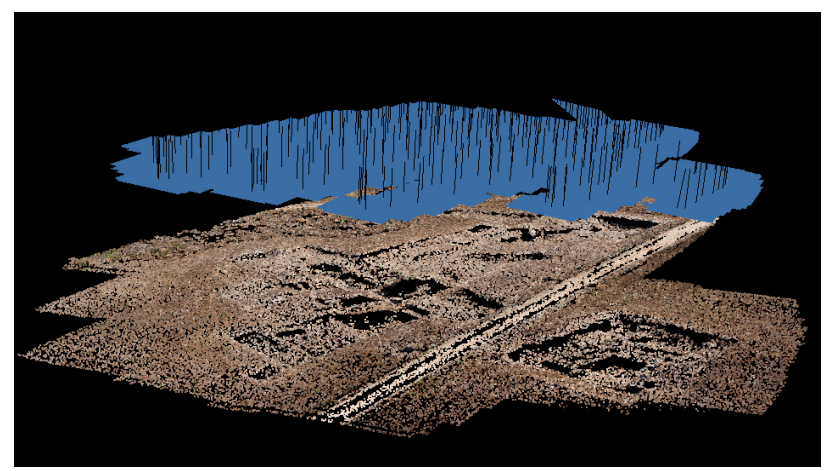

Figure 12. Camera position of the area of north-western fortifications and thermal baths flight.

\begin{tabular}{|c|c|c|c|c|c|}
\hline \multirow{2}{*}{ Project } & \multicolumn{2}{|c|}{$\begin{array}{c}\text { Number of } \\
\text { GCPs/CPs }\end{array}$} & $\begin{array}{c}\text { East } \\
\text { RMSE } \\
\text { [cm] }\end{array}$ & $\begin{array}{c}\text { North } \\
\text { RMSE } \\
{[\text { [cm] }}\end{array}$ & $\begin{array}{c}\text { Height } \\
\text { RMSE } \\
{[\mathbf{c m}]}\end{array}$ \\
\hline \multirow{3}{*}{ Insulae I, II and III } & $\mathrm{GCP}$ & 9 & 1.08 & 0.84 & 2.08 \\
\cline { 2 - 6 } & $\mathrm{GP}$ & 5 & 1.05 & 0.96 & 3.00 \\
\hline \multirow{2}{*}{\begin{tabular}{c} 
Decumanus maximus \\
\cline { 2 - 6 }
\end{tabular}} & $\mathrm{GCP}$ & 12 & 1.26 & 0.82 & 1.68 \\
\cline { 2 - 6 } & $\mathrm{GP}$ & 5 & 0.88 & 0.80 & 1.71 \\
\hline $\begin{array}{c}\text { Archaeological area of } \\
\text { "San Giovanni" }\end{array}$ & $\mathrm{GCP}$ & 4 & 1.36 & 0.79 & 0.13 \\
\cline { 2 - 6 } & $\mathrm{GP}$ & 3 & 0.47 & 1.01 & 0.73 \\
\hline $\begin{array}{c}\text { Area of north-western } \\
\text { fortifications and } \\
\text { thermal baths }\end{array}$ & $\mathrm{GCP}$ & 20 & 0.49 & 0.79 & 1.03 \\
\cline { 2 - 6 } & $\mathrm{CP}$ & 12 & 0.89 & 0.80 & 0.94 \\
\hline
\end{tabular}

Table 1. RMSE residuals of GCPs and CPs.

High-density point clouds, from triangulated object feature points, were computed with the high-quality setting, in order to use the original resolution of the images. Surface models from point clouds were generated and textured from the input images to provide a photorealistic representation of the scenes (Figure 13). The results from the photogrammetric process, for each surveyed area, are shown in Table 2.

Ortho-images were produced with a resolution ranging between $0.5 \mathrm{~cm}$ and $1 \mathrm{~cm}$ obtaining an appropriate level of detail for archaeological purposes (Figures 14-17).

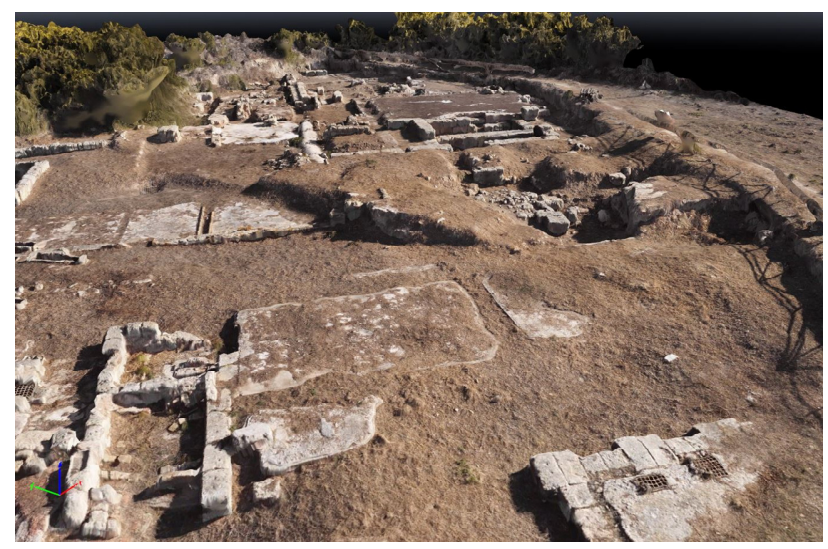

Figure 13. Detail of the textured 3D model of the Insulae II-III.

\begin{tabular}{|c|c|c|c|}
\hline Area of flight & $\begin{array}{c}\text { Number of } \\
\text { points of point } \\
\text { clouds }\end{array}$ & $\begin{array}{c}\text { Number of faces } \\
\text { of surface } \\
\text { models }\end{array}$ & $\begin{array}{c}\text { Ortho-images } \\
\text { resolution } \\
\text { [cm] }\end{array}$ \\
\hline Insulae I, II and III & 36.539 .810 & 1.000 .000 & 1 \\
\hline Decumanus maximus & 21.459 .836 & 221.847 & 1 \\
\hline $\begin{array}{c}\text { Archaeological area of } \\
\text { "San Giovanni" }\end{array}$ & 26.543 .512 & 1.809 .170 & 0.5 \\
\hline $\begin{array}{c}\text { Area of north-western } \\
\text { fortifications and } \\
\text { thermal baths }\end{array}$ & 125.000 .587 & 8.272 .723 & 0.5 \\
\hline
\end{tabular}

Table 2. Results of photogrammetric processes for each archaeological area. 


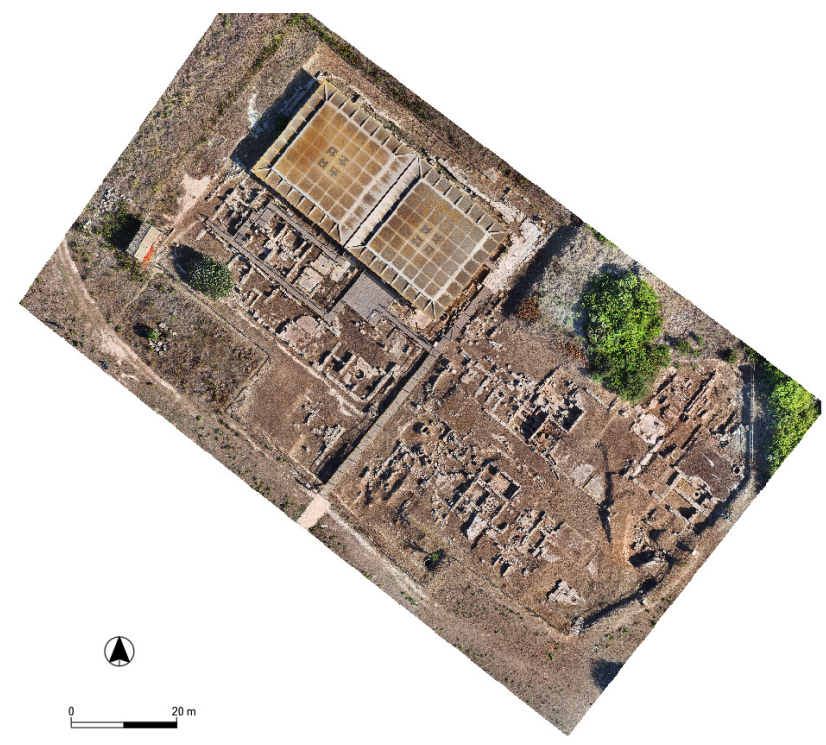

Figure 14. Ortho-image of the Insulae.

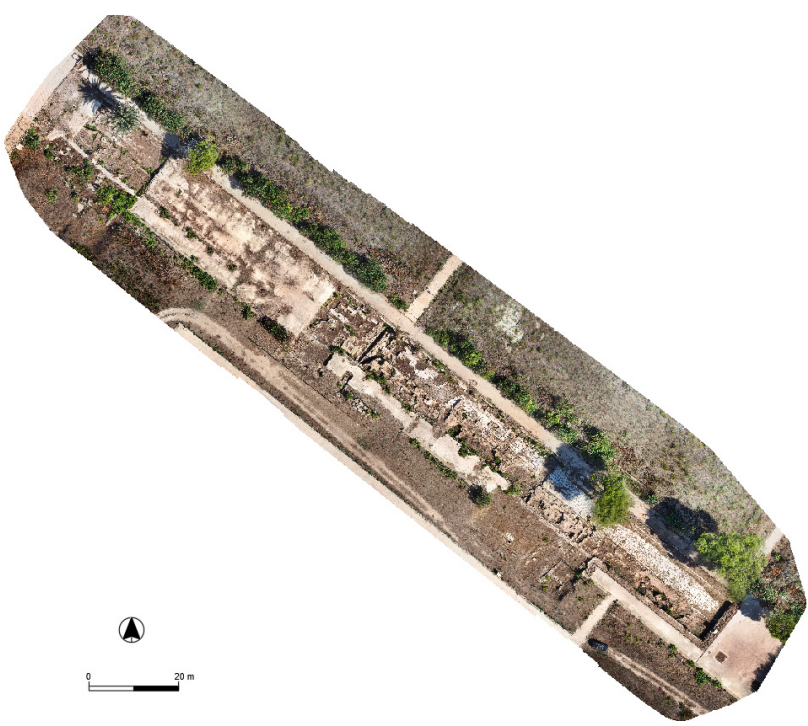

Figure 15. Ortho-image of the Decumanus maximus.

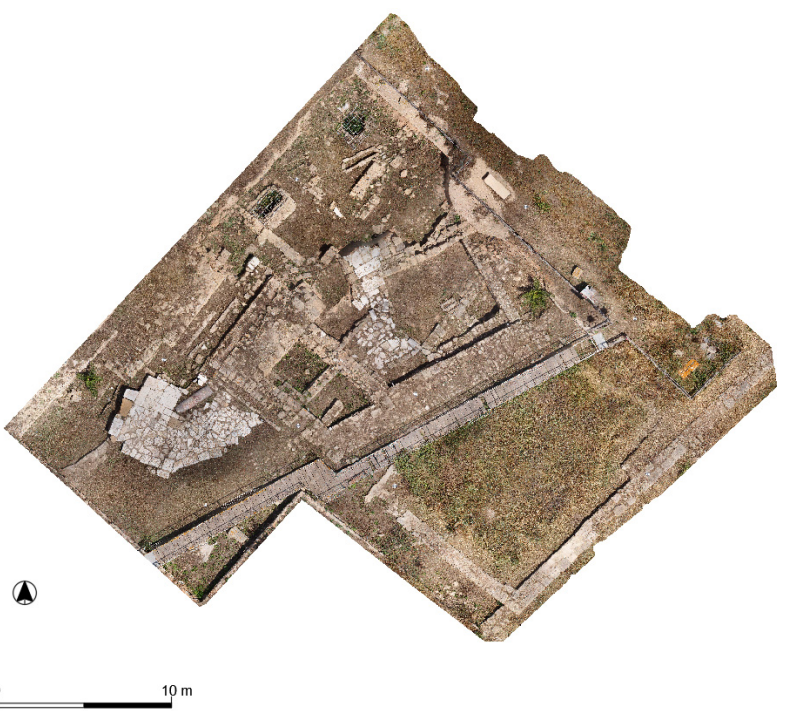

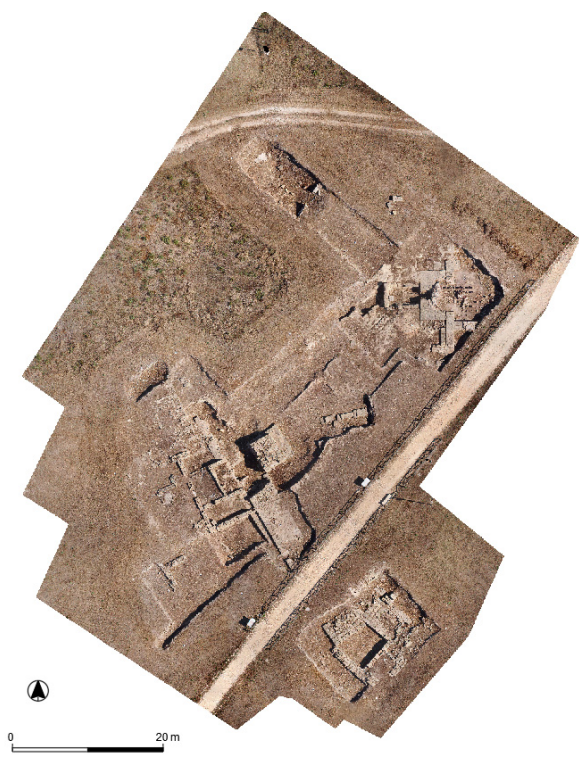

Figure 17. Ortho-image of the area of north-western fortifications and thermal baths.

\section{THE UAV DATA PRODUCTION FOR THE ARCHAEOLOGICAL STUDY}

All 3D products provide complete and usable documentation of archaeological sites and suggest completeness of geometric three-dimensional data from objects. For this reason, they become relevant to produce $2 \mathrm{D}$ representations.

The archaeological drawing plays an important role, but a traditional hand drawing can be affected by the choices and the viewpoint of the draftsman who decides how to draw and how to interpret the recorded objects.

The high speed of UAV systems and the flexibility given by 3D data offer a convenient way to complement or replace techniques presenting several limitations (Poux et al., 2017). 3D products can support the drawing phase and move the interpretation phase from the field to a post-processing step.

Moreover, the possibility to organize and consult $3 \mathrm{D}$ and $2 \mathrm{D}$ data in a GIS environment provides a more flexible and dynamic tool for the archaeologists.

In this context, with the aim of defining an archaeological map of Lilybaeum, the ortho-images of the surveyed archaeological areas of the Park were first employed to get 2D representations. Indeed, ortho-images were used in a GIS platform in order to produce updated plans. All elements were drawn to achieve a graphical layout (Figure 18).

A first interpretative analysis concerned the modern structures of the Park (streets, enclosures, walkways, etc.) and the ancient archaeological ruins. Moreover, the ancient remains have been distinguished according to their function (walls ruins, floors, streets, etc.) and/or, where is possible, according to their chronology (for example, in the case of the graves), in order to achieve complete plans (Figure 19). The employment of a GIS environment let an overlapping of new and previous data, as old plans, to link all resources (Figure 20). This will allow an immediate availability of all information and, finally, the realization of a future powerful search tool.

Figure 16. Ortho-image of the area of "San Giovanni". 


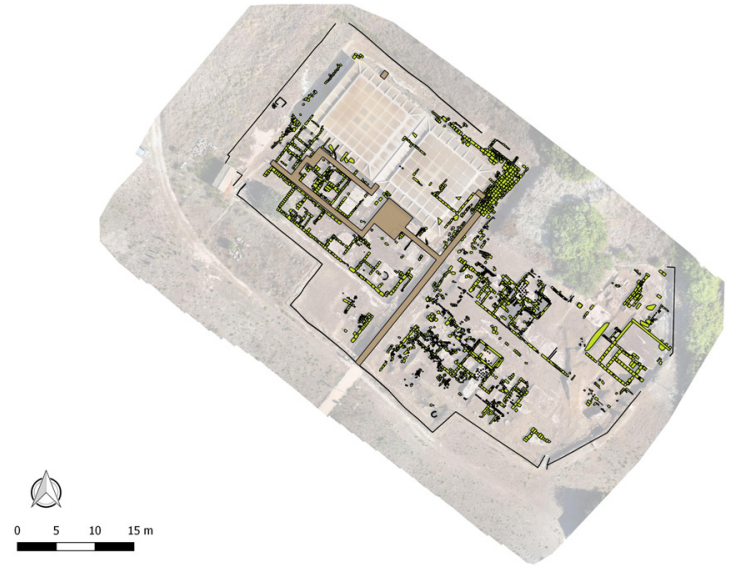

Figure 18. Vectorisation of the Insulae ortho-image.

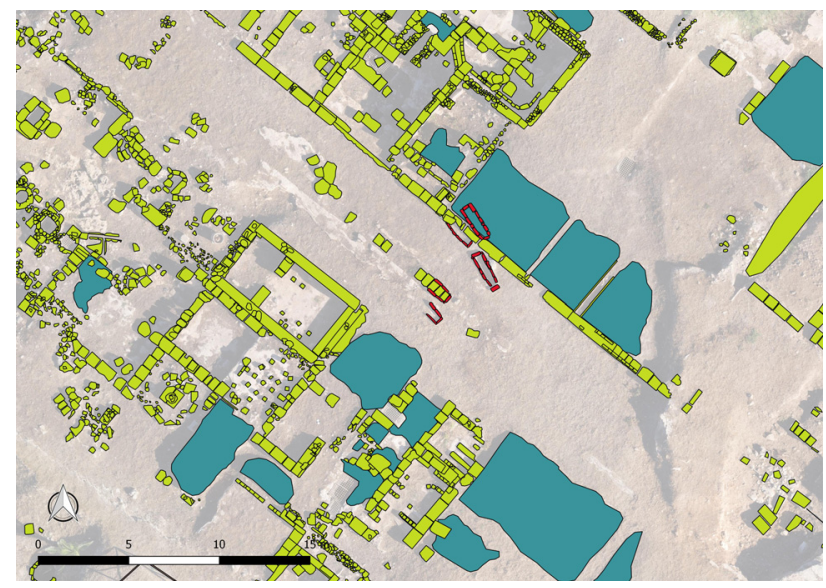

Figure 19. Classification of structures on the Insulae orthoimage (wall structures in green; floors remains in blue; graves in red).

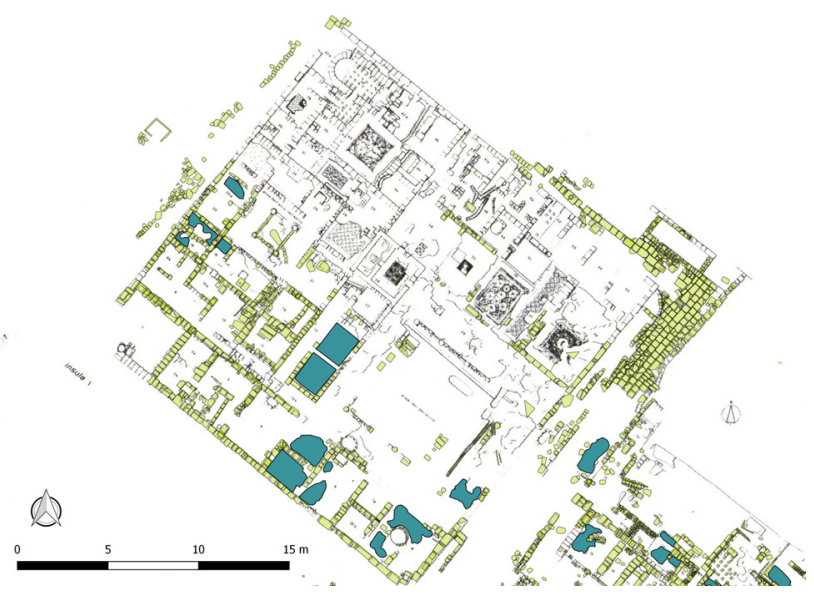

Figure 20. Overlap of an old plan of the Insula I on the new one.

\section{CONCLUSIONS}

The process of recording physical evidence is a fundamental step in archaeology for analysis and interpretation purposes. Documentation is closely related to the representation of objects. Indeed, the archaeological drawing plays an important role because is a moment of inspection of the object and it allows information to be displayed to let a subsequent reclaiming of the context. As a faithful representation of an object, archaeological drawing allows figuring exactly all visible characteristics and it must be objective and repeatable.

UAV systems became a useful approach to record large archaeological areas, in order to measure and completely document them. This technology provides improvements, applied to archaeology, in terms of data acquisition, versatility and accessibility. Moreover, an important change in archaeological workflow is the moving of interpretation from the field to a post-processing step.

The work described the UAV surveys carried out in the Archaeological Park of "Lilibeo". UAV system was employed, in a project aimed to the realization of the archaeological map of Lylibaeum, to generate accurate 3D products and highresolution ortho-images, in order to support and facilitate the acquisition of whole information on the archaeological remains of the Park. A complete 3D digital geometric recording was achieved based on 3D dense point clouds and 3D photorealistic models. 2D products were also created and integrated into a GIS platform to provide detailed drawings of the investigated areas, which can be used to provide a complete and usable documentation of the site.

With the final goal to realize the archaeological map of the site, the presented work is a first step aimed to document the archaeological remains in situ and to gather previous data. A GIS project has been planned to create, in this phase, 2D drawings directly from $3 \mathrm{D}$ accurate digital products and to collect and relate old and new data.

The accurate and complete documentation of the archaeological area of "Lilibeo" is a challenging task in order to promote the enjoyment of tourists, to favor his conservation and to prevent the risk of information's loss.

\section{ACKNOWLEDGEMENTS}

For the realization of this work the authors would like to express our gratitude to the "Polo Museale di Trapani". A special thank is due to Anna Maria Parrinello and Maria Grazia Griffo of the "Lilibeo - Baglio Anselmi" Regional Archaeological Museum". The authors are also grateful to Alessandra Garraffa and Fulvio Capodici who have piloted the UAV.

\section{REFERENCES}

Bitelli, G., Girelli, V.A., Sammarini, G., 2018. 4-dimensional recording and visualization of urban archeological excavations. Applied Geomatics, Volume 10, Issue 4, 415-426.

Brumana, R., Oreni, D., Van Hecke, L., Barazzetti, L., Previtali, M., Roncoroni, F., and Valente, R., 2013. Combined geometric and thermal analysis from UAV platforms for archaeological heritage documentation. ISPRS Ann. Photogramm. Remote Sens. Spatial Inf. Sci., II-5/W1, 49-54.

Chiabrando, F., D'Andria, F., Sammartano, G. and Spanò, A., 2017. UAV photogrammetry for archaeological site survey. 3D Models at Hierapolis in Phrygia (Turkey). Virtual archaeology Review, vol. 9, n. 18, 28-43.

Cowley, D. C., Moriarty, C., Geddes, G., Brown, G. L., Wade, T., and Nichol, C., 2017. UAVs in Context: Archaeological Airborne Recording in a National Body of Survey and Record. Drones, vol. 2, Issue 1, 1-16.

Erenoglu, R.C., Akcaya, O., Erenoglub, O., 2017. An UASassisted multi-sensor approach for 3D modeling and 
reconstruction of cultural heritage site. Journal of Cultural Heritage, 26 (2017), 79-90.

Fernández-Hernandez, J., González-Aguilera, D., RodríguezGonzálvez, P., Mancera-Taboada, J., 2015. Image-Based Modelling from Unmanned Aerial Vehicle (UAV) Photogrammetry: An Effective, Low-Cost Tool for Archaeology Applications. Archaeometry, 57 (1), 128-145.

Giglio, R., Vecchio, P., 2004. Nuovi dati su Lilibeo ellenistica. In: Sicilia Ellenistica, Consuetudo Italica. Alle origini dell'architettura ellenistica d'occidente. Atti delle giornate di studio (Spoleto, 5-7 novembre 2004). A cura di Massimo Osanna, Mario Torelli. Biblioteca di "Sicilia Antiqua" I,. 123131.

Giglio, R., 2011. Marsala e Lilibeo: due città in una. In: Gli scavi archeologici dell'Amministrazione comunale, Marsala 2011.

Herrmann, J.T., Glissmann, B., Sconzo, P., Pfälzner, P., 2018. Unmanned Aerial Vehicle (UAV) Survey with CommercialGrade Instruments: A Case Study from the Eastern Habur Archaeological Survey, Iraq. Journal of Field Archaeology, 43:4, 269-283.

Lo Brutto, M., Garraffa, A., and Meli, P., 2014. UAV platforms for cultural heritage survey: first results. ISPRS Ann. Photogramm. Remote Sens. Spatial Inf. Sci, II-5, 227-234.

Lo Brutto, M., Sciortino, R., and Garraffa, A., 2017. RPAS and TLS techniques for archaeological survey: the case study of the archaeological site of Eraclea Minoa (ITALY), Int. Arch. Photogramm. Remote Sens. Spatial Inf. Sci., XLII-2/W3, 433438.

Lo Brutto, M., Ebolese, D., and Dardanelli, G., 2018. 3D modelling of a historical building using close-range photogrammetry and Remotely Piloted Aircraft System (RPAS). Int. Arch. Photogramm. Remote Sens. Spatial Inf. Sci., XLII-2, 599-606.

Nikolakopoulos, K.G., Soura, K., Koukouvelas, I.K., Argyropoulos, N.G., 2017. UAV vs classical aerial photogrammetry for archaeological studies. Journal of Archaeological Science: Reports, 14, August 2017, 758-773.

Poirier, N., Hautefeuille, F., Calastrenc, C., 2013. Low Altitude Thermal Survey by Means of an Automated Unmanned Aerial Vehicle for the Detection of Archaeological Buried Structures. Archaeological Prospection, 20(4), 303-307.

Poux, F., Neuville, R., Van Wersch, L., Nys, G. A., Billen, R., 2017. 3D Point Clouds in Archaeology: Advances in Acquisition, Processing and Knowledge Integration Applied to Quasi-Planar Objects. Geosciences, 7, 96, 1-32.

Richards-Rissetto, H., 2017. What can GIS + 3D mean for landscape archaeology?. Journal of Archaeological Science, 84, 10-21.

Rocha, L. and Branco, G., 2009. Archaeological maps: methods and techniques for territorial analysis. ArcheoSciences, 33 (suppl.), 141-142.

Tscharf, A., Rumplerb, M., Fraundorferb, F., Mayera, G., Bischofb, H., (2015). On the Use of UAVs in Mining and Archaeology - Geo-Accurate 3D Reconstruction Using Various Platforms and Terrestrial Views. In: ISPRS Annals of the Photogrammetry, Remote Sensing and Spatial Information Sciences, Vol. II-1/W1, pp. 15-22. 